Intl. Trans. in Op. Res. xx (2019) 1-24

\title{
Manufacturer Defensive and Offensive Advertising in Competing Distribution Channels
}

\author{
Guiomar Martín-Herrán ${ }^{\mathrm{a}}$ and Simon-Pierre Siguéb,* \\ E-mail: guiomar@eco.uva.es [Guiomar Martín-Herrán]; simon.sigue@fb.athabascau.ca [Simon-Pierre Sigué]
}

\begin{abstract}
This paper investigates how two competing manufacturers should invest in defensive and offensive advertising in a two-segment market and whether they should each adopt a decentralized or an integrated channel if their goal is to maximize total channel profits. We find that, manufacturers in decentralized channels can exclusively undertake either of the two types of advertising or combine the two at the equilibrium. In integrated channels, they can either combine the two or exclusively undertake defensive advertising. When multiple equilibria exist, strategies that combine both types of advertising should be preferred to exclusive defensive advertising strategies, which are better than exclusive offensive advertising strategies. Also, total channel profits are higher in decentralized channels than in integrated channels when the brands are moderately or highly substitutable. Conversely, total channel profits of integrated channels are higher than those of decentralized channels in areas where the brands are relatively differentiated and the offensive advertising retaliatory capacity of the rival is stronger. Theoretical and managerial implications of these findings are discussed.
\end{abstract}

Keywords: advertising targeting; competition; distribution channel; defensive advertising; offensive advertising.

\section{Introduction}

Increasingly, firms distinguish between consumers who purchase or are more likely to purchase their products and those who purchase or are more likely to purchase from their rivals. These firms have the strategic option to either target exclusively one of these two market segments or both at the same time to achieve their marketing goals. The pursuit of any of these strategic options generally affects product, pricing, marketing communications, and distribution decisions as firms strive to develop distinctive positioning to effectively appeal to the selected market segment(s). This research, as other studies before it, focuses on advertising targeting (e.g., Iyer et al., 2005; Wang et al., 2001; Zhang et al., 2016). Because several firms spend substantial shares of their marketing budgets on advertising, finding optimal advertising targeting schemes is of great interest for both managers and researchers.

\footnotetext{
*Author to whom all correspondence should be addressed (e-mail: simon.sigue@ fb.athabascau.ca).
} 
Conventional knowledge in marketing strategy claims that differentiated marketing strategies adapted to each market segment tend to be more effective, but suffer from high costs; concentrated marketing strategies that focus only on a single or a few market segments fit companies with limited resources, but may not be viable due to their limited market coverage; and finally, undifferentiated marketing strategies that treat the whole market as a single segment tend to be cheaper, but could also be less effective where consumer preferences are heterogeneous. However, this conventional knowledge remains however very generic and cannot serve as a practical framework for advertising targeting, especially in a competitive context. A few analytical works have investigated directly or indirectly advertising targeting in various contexts (e.g., Erickson, 1993; Iyer et al., 2005; Martín-Herrán et al., 2012; Wang et al, 2011; Zhang et al, 2016). For instance, in a duopoly market, Iyer et al. (2005) found that advertising targeting that focuses on consumers whose preference match a product's attribute is more effective than a uniform advertising run across segments. In a bilateral monopoly, Zhang et al. (2016) found that advertising targeting, compared to uniform advertising directed to the whole market, increases the manufacturer profit at the expense of the retailer. However, many of these previous works do not offer advertisers the possibility to use differentiated advertising programs to target different market segments. Some exceptions include the works by Erickson (1993), Martín-Herrán et al. (2012), and Martín-Herrán and Sigué (2018), which allow competitors, in a market share rivalry, to use offensive and defensive advertising to respectively attack the rival's market share and defend their own market share. Comparing the outcomes of advertising targeting in a single market segment to the outcomes of running the same advertising in the whole market when consumers have different brand preferences may lead to suboptimal advertising strategies (e.g., Iyer et al, 2005). In particular, it can lead to the belief that advertising to consumers who mainly prefer rivals' products is wasting advertising money as these consumers ultimately buy from those rivals. This belief goes against the conventional wisdom that supports the use of differentiated marketing strategies in heterogeneous markets. Also, it is not consistent with some business practices, such as the use of comparative advertising where the obvious goal of the advertiser is to change customer preferences (see, Shaffer and Zettelmeyer (2009)).

To challenge the above belief and investigate other issues related to vertical interactions on advertising targeting, we have developed an analytical model of two competing channels, in which a manufacturer deals with an exclusive retailer who sells a competing brand in a market. The market is divided into two groups of consumers. Without advertising, consumers who prefer one brand are less likely to prefer the competing brand and vice versa. There are a few consumers, in between, who can purchase either brand, but their role is negligible. Building on Erickson (1993),Martín-Herrán et al. (2012) and Martín-Herrán and Sigué (2018), we consider that manufacturers in the two channels have the possibility of undertaking two differentiated advertising programs targeted to these two market segments. Advertising targeted to own customer base is called defensive advertising as it stimulates demand from consumers who naturally prefer the brand and, by so doing, limits the effects of any advertising assault from the rival. Advertising targeted to consumers who naturally prefer the rival's product is called offensive advertising and aims mainly to expand a firm's customer base at the expense of the rival. In addition, the model considers that a consumer's preference toward a given brand depends, among others, on the retail price set by the exclusive retailer. In such a configuration, several factors may influence advertising targeting and investments, including horizontal competition across channels, vertical externalities within channels, and the relative strength of the competitors. This research hopes to identify some of these factors by answering the following questions: 
1. Should manufacturers, in both decentralized and integrated channels, exclusively direct their advertising efforts either to their own customer base or the rival's customer base, or should they simultaneously advertise to the two market segments at the equilibrium?

2. What should the optimal channel structure be if channel members act so as to maximize total channel profits?

Answering to the above questions expands our current knowledge base on advertising targeting by identifying the conditions under which competing manufacturers, in decentralized and integrated channels, can adopt differentiated advertising approaches that appeal specifically to different market segments. This paper is related to previous research in competitive advertising as follows. First, works based on the traditional Lanchester model investigate offensive advertising investments when firms battle for market shares over time (See, Huang et al. (2012) for a review). Some extensions of these works study both offensive and defensive advertising (e.g., Erickson 1993, Martín-Herrán et al., 2012). Their findings describe how competitive firms should optimally invest in both offensive and defensive advertising as their market shares evolve over time. For instance, Martín-Herrán et al. (2012) report findings that support the view that a firm may find it optimal to exclusively undertake either one of the two types of advertising or combine the two at the same moment over time. However, this body of research overlooks critical aspects considered in this study, including the role of retailers, pricing decisions, and customer preferences in advertising competition.

Second, a central question of this research is whether to target consumers who have a strong preference for the firm's brand and/or those who primarily prefer the rival's brand. Iyer et al. (2005) studied a similar question in a context where competing firms can either focus their advertising on their customer bases or expand it to cover the entire market. They found that, compared to the situation where advertising is done to uniformly cover the entire market, advertising that exclusively focuses on the firm's own customer base increases equilibrium profits due to enhanced effectiveness and brand differentiation. Martín-Herrán and Sigué (2018) allowed the competitors to consider both defensive and offensive advertising to respectively target their own and their rival's customer bases. However, these two works overlook vertical interactions. On the other hand, Zhang et al. (2016) investigated advertising targeting in a bilateral monopoly. They adopted Iyer et al.'s definition of advertising targeting in the context where advertising is mainly informative. Their findings indicate that, when vertical interactions are considered, a profit maximizing manufacturer may adopt targeted advertising or uniform advertising depending on some identified conditions. This latter work did however disregard competition, which is a key ingredient of our research. Moreover, the manufacturer did not have the opportunity to undertake two types of advertising that can specifically appeal to each market segment as we do in this research.

Third, another group of studies has focused on the persuasive role of advertising in the context of competition in a channel structure where competing manufacturers sell their product through a single dealer (e.g., Shaffer and Zettelmeyer, 2004; Wu et al., Wang 2009). These works investigate whether channel members are better or worse off with manufacturers' advertising activities that increase brand differentiation or increase transportation costs in Hotelling-type models (Hotelling, 1929). Their findings support the view that the impact of persuasive advertising on channel members' profits depend on the target market segments. In particular, Wu et al. (2009) found that persuasive advertising can lead to a Pareto improvement along the entire distribution channel if targeted wisely. Exploring this research further, Shaffer and Zettelmeyer (2009) studied whether two competing manufacturers in a distribution channel should undertake comparative or noncomparative advertising. They found that, all else being 
equal, a manufacturer prefers comparative to noncomparative advertising when advertising is targeted to their own customer base, while noncomparative advertising is preferred when advertising is directed to their rival's customer base. Departing from this research, we study a channel structure in which manufacturers sell their products to two exclusive dealers. As a result, we are able to compare integrated and decentralized channel performances. Moreover, while we also use a Hotelling-type model, advertising is more informative in our model and does not directly affect brand differentiation.

Finally, the issue of whether marketing channels should be decentralized or integrated (coordinated) has been heavily investigated in the literature. In bilateral monopoly contexts, integrated channels are known to perform better than decentralized channels as they do not suffer from vertical externalities such as double marginalization and under-investment in advertising (e.g., Ingene et al, 2012). McGuire and Staelin (1983) demonstrated that when competition is considered both at the manufacturers' and retailers' levels, decentralized channels may perform better due to the fact that independent retailers attenuate price competition between highly substitutable products. Since then, several works have been undertaken along this line to test the robustness of this theory (e.g., Coughlan, 1985; Moorthy, 1988; Trivedi, 1998; Wang et al., 2011; Zhang et al., 2012). This paper shares some similarities with the papers by Wang et al. (2011) and Zhang et al. (2012), which investigated whether decentralized channels could still perform better than integrated channels when competition between channels goes beyond prices to also include advertising. Wang et al. (2011) found that, channel decentralization may intensify advertising competition and damage channel profits. In such a context, in opposition to McGuire and Stealin's theory, channel integration is preferred over channel decentralization. These authors consider persuasive advertising, which increases consumers' gross valuation of the advertised brand. Zhang et al. (2012) obtained opposite findings with informative advertising, i.e., decentralization improves channel profits when products are highly substitutable. Studying the profitability of cooperative advertising in the same channel structure, Karray et al. (2017) recently found that a cooperative advertising offer can also help a decentralized channel achieve a better performance than an integrated channel when products are highly substitutable. Building on these previous works, we use informative advertising and consider that the manufacturers can conduct offensive and defensive advertising directed at two different market segments. This allows us to investigate differentiated advertising targeting strategies that are overlooked in the current literature. In addition, we also examine the impact of the relative power of competitors and the relative effectiveness of offensive and defensive advertising on targeting decisions.

The rest of this paper is organized as follows. Section 2 describes the model. Section 3 presents the equilibrium advertising strategies for decentralized channels, while Section 4 does the same for integrated channels. Section 5 identifies the conditions under which competing manufacturers prefer channel decentralization to channel integration. Section 6 offers conclusions and discusses theoretical and managerial implications.

\section{The model}

We consider a local market with $n$ potential consumers who can purchase two brands manufactured by two competing manufacturers of the same product via two exclusive dealers. Consumers can only purchase one unit of the product and differ in their preferences over the two brands on a single attribute. In particular, Brand $i$ performs very well on this attribute and obtains the highest score, which is 1 , while 
Brand $j$ 's performance is not as good as the first and is given the score of 0 . Consumers' preferences toward these two brands are distributed uniformly along these two extremes. Therefore, consumers who like one brand the most like the other the least. They incur a "transportation cost", $t$, per unit of distance traveled from their ideal product. The parameter $t$ captures consumer sensitivity to the product's attribute. Consumers preferring the product at both extremes make their purchase without bearing any transportation cost. Denoting by $v$ the gross value attached to using a unit of either of the two brands, consumers who prefer Brand $i$ derive a utility $v-p_{i}$ from purchasing it from Dealer $i$ and a utility $v-t-p_{j}$ from purchasing Brand $j$ from Dealer $j$, where $p_{i}$ and $p_{j}$ are the retail prices of the two brands.

Consumers purchase a brand of this product only if it gives them a positive surplus. Therefore, the marginal consumer whose ideal product is located at a distance, $d \in[0,1]$, is indifferent buying either brand if $d$ meets the following condition: $v-p_{1}-t d=v-p_{2}-t(1-d)$. As a result, we obtain the following:

$$
d=\frac{t-\left(p_{1}-p_{2}\right)}{2 t}
$$

Ideally, consumers whose ideal products are located on the left hand side of $d$ purchase from Brand 1, while those whose ideal products are located on the right hand side of $d$ prefer Brand 2. Therefore, if we denote $x_{i}$ the market base of Brand $i$, we obtain $x_{1}=d$ and $x_{2}=1-d$. The market base of Brand $i$ can be considered as its potential market share and represents the percentage of customers who can purchase this brand at the market price if everything else is equal:

$$
x_{i}=\frac{t-\left(p_{i}-p_{j}\right)}{2 t}, \quad i, j=1,2, i \neq j .
$$

The market bases of the two brands therefore depend on their retail prices. We consider that dealers do not price-discriminate and apply the same price to all consumers regardless of their brand preference. Alternatively, targeted pricing based on consumers' preference could be used (e.g., Iyer et al., 2005; Zhang et al., 2016), but will distract us from the main focus on this research, which is the analysis of optimal offensive and defensive advertising strategies.

Given consumers' preferences across brands, the manufacturer $i$ sets a wholesale price, $w_{i}$, and undertakes defensive $\left(D_{i}\right)$ and/or offensive $\left(O_{i}\right)$ advertising to stimulate demand, given by:

$$
q_{i}=n x_{i} g_{i}\left(O_{j}, D_{i}\right)+n x_{j} l_{i}\left(O_{i}\right), \quad i, j=1,2, i \neq j,
$$

where $g_{i}\left(O_{j}, D_{i}\right)$ is a positive and negative function of $D_{i}$ and $O_{j}$, respectively, while $l_{i}\left(O_{i}\right)$ is a positive function of $O_{i}$. Whether offensive or offensive, the advertising does not aim at changing consumers' preferences in this setup. In this sense, it is not persuasive as defined in some previous works (e.g., Shaffer and Zettelmeyer, 2004; Wu et al., 2009). Consumers are also aware of the two brands and their distinctive characteristics. The role of both defensive and offensive advertising is similar to reminder advertising, which aims at keeping a brand at the top of consumers' minds in a mature market (Iyer et al., 2005). This characterization of advertising is consistent with Lanchester-type models in which firms primarily battle to stay in consumers' minds at the time of purchase. Offensive advertising that appeals to the rival's market base is essentially combative. Therefore, while some consumers in a firm's market 
may be very committed to a brand, in some cases, defensive advertising targeted at their own market base could be necessary to limit the effects of the rival's assault in consumers' minds and to stimulate demand from less committed consumers. Remember, the two dealers also influence the demand functions through their retail prices, which affects the size of each manufacturer's customer base.

For simplicity, we choose the following specifications for the functions $g_{i}\left(O_{j}, D_{i}\right)$ and $l_{i}\left(O_{i}\right)$ :

$$
g_{i}\left(O_{j}, D_{i}\right)=-\delta \sqrt{O_{j}}+\sqrt{D_{i}} \text { and } l_{i}\left(O_{i}\right)=\theta \sqrt{O_{i}} .
$$

The parameters $\theta$ and $\delta$ are non-negative and respectively denote the firm's own and the rival's offensive advertising effects on the demand functions. While we do not make any a priori assumption on the relative importance of the parameters $\theta$ and $\delta$, the difference, $\theta-\delta$, could be considered as an indicator of the intensity of the retaliatory attack of the rival. When $\theta=\delta$, a firm can respond in kind or with the same strength to an offensive advertising assault from the rival. Alternatively, when $\theta>\delta$ or $\theta<\delta$, the attacker's offensive advertising is more or less powerful than that of the rival. We therefore consider the general case when a firm initiates an offensive advertising attack, it can expect its rival to react either with an identical offensive advertising response or with a stronger or weaker offensive advertising response. On the other hand, the effect of defensive advertising is normalized to 1 . Conventional wisdom in marketing assumes that defensive marketing activities or marketing activities targeted to a firm's own customer base are more effective than those aiming to attract competitors' customers. On this basis, we consider that the effectiveness of offensive advertising is, at best, equal to that of defensive advertising, i.e., $\theta \leq 1$.

Concave functions are used to take into account the decreasing returns on investments in both offensive and defensive advertising (e.g., Karray, 2013). The parameters $c_{1}$ and $c_{2}$ denote the unitary cost of both offensive and defensive advertising activities, respectively, and are also non-negative. We assume identical unitary advertising costs across channels. Offensive and defensive advertising costs enter linearly in the manufacturers' profit functions below. As it is common in the marketing channel literature, we normalize the production and other administrative costs to zero. The manufacturer's and retailer's profits for each brand are given by:

$$
M_{i}=w_{i} q_{i}-c_{1} O_{i}-c_{2} D_{i}, \quad R_{i}=\left(p_{i}-w_{i}\right) q_{i}, \quad i, j=1,2, i \neq j,
$$

The symmetry of the problem leads us to focus on symmetric equilibria, hence channel members make identical decisions, i.e., $O_{1}=O_{2}=O, D_{1}=D_{2}=D, p_{1}=p_{2}=p$, and $w_{1}=w_{2}=w$. As a result, demand and profit functions become:

$$
q=n x((\theta-\delta) \sqrt{O}+\sqrt{D}), \quad M=w q-c_{1} O-c_{2} D, \quad R=(p-w) q .
$$

Observe that when $\theta-\delta \geq 0$, meaning that a firm's offensive advertising is either of the same strength or stronger than that of the rival, its demand function is always positive. Conversely, if the rival's offensive marketing is stronger,i.e. $\theta<\delta$, defensive marketing plays a key role for the survival of the firm as its demand could be reduced to zero. The model specification above implies that the two firms get zero demands and profits if they do not carry out any of the two types of advertising. This simplification is made to allow us to focus on the impact of offensive and defensive advertising on channel competition, which is the distinctive contribution of this research. As we have assumed a 
mature market, one can easily add a constant term to the demand function to indicate that demands remain unchanged if the two firms do not advertise. However, such a specification will not change the qualitative findings of our simplified model.

\section{Decentralized channels}

This section investigates the type of advertising activities manufacturers should undertake at the equilibrium in decentralized channels in which channel members separately set their respective decision variables so as to maximize their individual profits. As is common in the marketing literature, in each channel, the manufacturer acts first as the channel leader and the retailer responds to the manufacturer's move as the follower. A Stackelberg game is therefore played between the manufacturer and retailer in each channel. Members of the two channels compete both at the manufacturer and retailer levels. We use the Nash equilibrium concept as the players simultaneously set their decision variables at each level.

We are able to analytically characterize two equilibria that correspond to the corner solutions where the two manufacturers exclusively undertake either offensive advertising or defensive advertising (see Appendix A). Hereafter, these two equilibria are respectively called Exclusive Offensive Advertising (EOA) and Exclusive Defensive Advertising (EDA) equilibria. The interior solution for the game where competing manufacturers simultaneously invest in both offensive and defensive advertising cannot be analytically characterized, except in the scenario where $\delta=\theta$. However, we have developed an algorithm to numerically characterize the interior solution of this game. This solution is called Offensive-Defensive Advertising (ODA) equilibrium.

The players' strategies and profits for these three equilibria depend on the game parameters, including $n, t, c_{1}, c_{2}, \delta$, and $\theta$. This implies that some restrictions need to be imposed on the parameters to satisfy the concavity conditions and obtain non-negative profits, positive price, advertising efforts, and demands as well as to ensure that the sales of the two dealers do not exceed the number of potential consumers. As a matter of fact, it can easily be proven that the EOA equilibrium is only feasible if the following condition is satisfied: $\theta<\delta<3 \theta$. Given the complexity of the necessary conditions, we numerically analyze the feasibility of the three equilibria in the following figures. To achieve this goal, we fix $n=1$ and $c_{1}=1$ and identify the feasibility regions for the different equilibria for three different values of $c_{2}=0.25,0.5,0.75$, while varying the parameters $t$ and $\theta$ in the following ranges: $t \in(0,4]$, and $\theta \in[0,1]$.

Figures $1 \mathrm{a}, 1 \mathrm{~b}$, and $1 \mathrm{c}$ illustrate the scenario where $\delta=\theta$, meaning the two manufacturers have the same offensive strength. In other words, an attack by a manufacturer is met by a response of identical strength from the rival.

Similar figures are obtained for the scenario where a firm's offensive advertising is more effective than that of the rival $(\delta=0.5 \theta)$. Thus, the following discussion also applies to this scenario. Figures $1 \mathrm{a}, 1 \mathrm{~b}$, and 1c confirm the analytical finding that the EOA equilibrium is not feasible in this area of the parameter space. An exclusive attack on the rival's customer base when he can retaliate with the same or smaller intensity is not advisable because both manufacturers would engage in an offensive advertising war that would lead to wasteful offensive advertising expenditures that would be reciprocally canceled out. On the other hand, there are three different areas in Figures 1a, 1b, and 1c. In the largest area, none of the three equilibria is feasible. This area is associated with higher transportation costs. Therefore, 

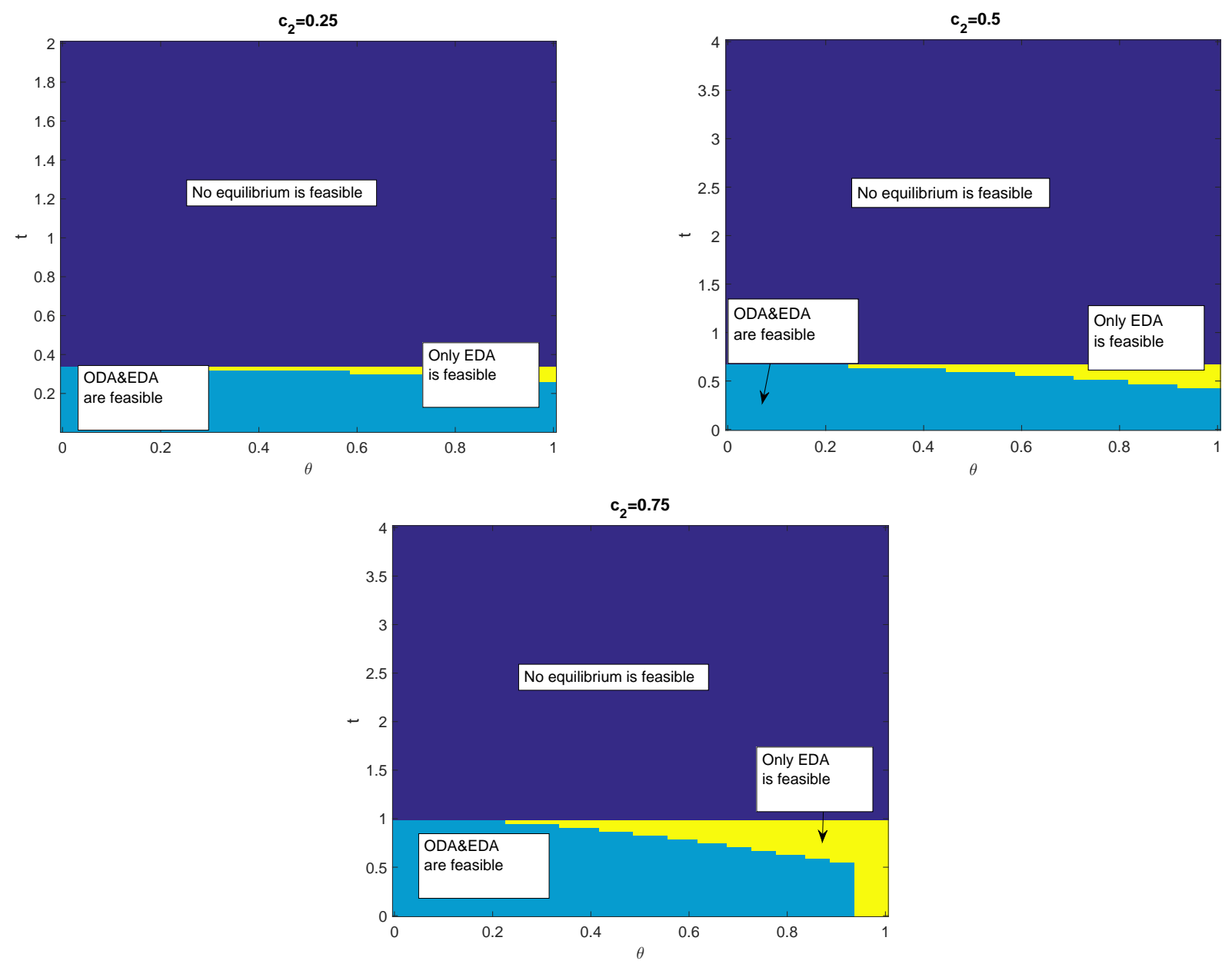

Fig. 1. Feasibility scenario $\delta=\theta$ for different values of $c_{2}$. First line, Figure 1a $c_{2}=0.25$ left; Figure $1 \mathrm{~b} c_{2}=0.5$ right. Second line, Figure 1c $c_{2}=0.75$.

everything else being equal, manufacturers do not undertake both offensive and defensive advertising if the two brands are highly differentiated. This prevents manufacturers from spending heavily to attract the rival's customers and investing to keep the customers who prefer their brand. In the other two areas, the two brands are highly or moderately substitutable; either both the EDA and ODA equilibria are simultaneously feasible or the EDA equilibrium is feasible alone. The feasibility area increases with the cost of defensive advertising. Higher defensive advertising costs prevent manufacturers from defending heavily and increase opportunities to the rival's attack even when the brands are relatively well differentiated. The relative effectiveness of offensive advertising with respect to defensive advertising also plays a key role. The area of feasibility of the ODA equilibrium decreases as the relative effectiveness of offensive advertising grows. Depending on the other parameters, the EDA equilibrium becomes the unique equilibrium if the effectiveness of offensive advertising is large enough or identical to that of defensive marketing. This suggests that, knowing that customers can easily move from one brand to another due 
to offensive advertising, competitors find it optimal to concentrate their advertising efforts on consumers who primarily prefer their brand.

On the other hand, when a firm's offensive advertising is less effective than that of the rival $(\delta=1.5 \theta)$, the conditions under which the equilibria are feasible change drastically, as illustrated in Figures $2 a, 2 b$, and $2 \mathrm{c}$.
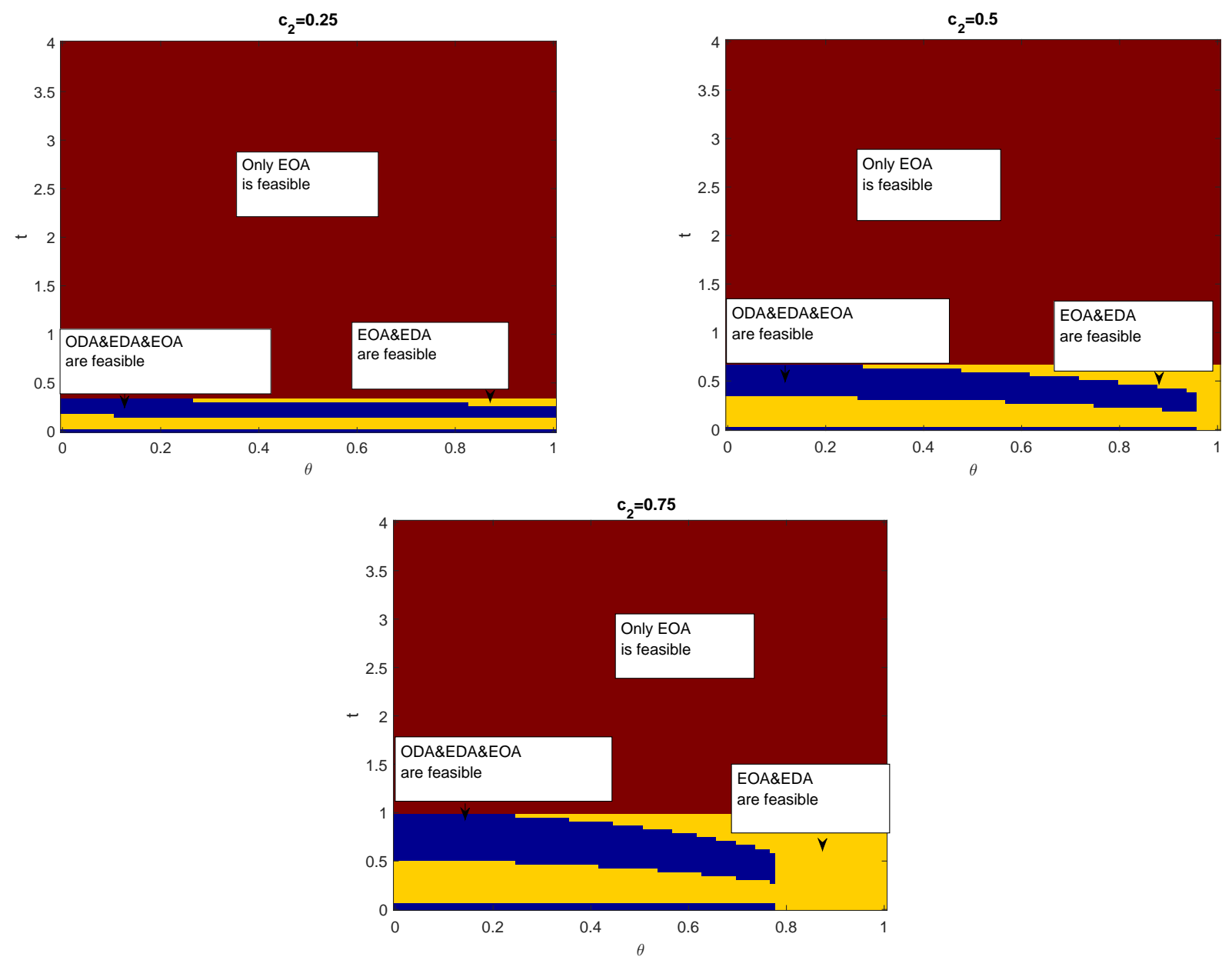

Fig. 2. Feasibility scenario $\delta=1.5 \theta$ for different values of $c_{2}$. First line, Figure $2 \mathrm{a} c_{2}=0.25$ left; Figure $2 \mathrm{~b} c_{2}=0.5$ right. Second line, Figure 2c $c_{2}=0.75$.

In Figures 2a, 2b, and 2c, the EOA equilibrium is now always feasible, while the EDA and ODA equilibria, everything being equal, could only be feasible when the products are relatively undifferentiated. This can be explained by the firm's need to protect their own customer base from the rival's attack when the products are substitutable. Surprisingly, manufacturers invest in offensive advertising even for well differentiated products when the retaliatory capacity of the rival is strong.

The existence of multiple equilibria in some areas of the parameter space raises the question of which equilibrium should be implemented by profit maximizing manufacturers. We postulate that each man- 
ufacturer, acting as a channel leader, should implement the equilibrium that provides the greatest profits. Considering the feasibility conditions discussed above, we numerically compare the manufacturers' profits for the ODA, EOA and EDA equilibria. Our findings are summarized in the following claims.

Claim 1. In scenarios where $\delta=\theta$ and $\delta=0.5 \theta$, manufacturers prefer the ODA equilibrium to the EDA equilibrium, which is implemented only when it is the unique equilibrium. The EOA is unfeasible.

Claim 2. In scenarios where $\delta=1.5 \theta$, manufacturers prefer the ODA equilibrium to the EDA equilibrium, which is also preferred to the EOA equilibrium. The EOA equilibrium is played only when it is the unique equilibrium.

Obviously, manufacturers may implement either of the three equilibria depending on the values of the game parameters. In the presence of multiple equilibria, the ODA equilibrium should come first followed by the EDA equilibrium. The EOA equilibrium should only be considered if neither of the other two equilibria is feasible. This could only occur when the products are weakly substitutable and the offensive advertising of the rival is more effective. The comparisons of the players' strategies in areas where multiple equilibria exist reveal that ODA strategies, i.e., $p^{O D A}, w^{O D A}, D^{O D A}$ and $O^{O D A}$, are always higher than the corresponding EDA and EOA strategies. Also, EDA strategies ( $p^{E D A}$ and $w^{E D A}$ ) are always higher than the corresponding EOA strategies $\left(p^{E O A}\right.$ and $\left.w^{E O A}\right)$. Thus, the adoption of the EOA equilibrium in decentralized channels, which is synonymous with engaging in an advertising war, brings prices down for both manufacturers and dealers compared to the EDA equilibrium and damages the manufacturers' profits. Conversely, the adoption of the ODA equilibrium leads to heavy investments in offensive and defensive advertising that allow manufacturers to fully cover the entire market, charge higher prices, and enhance their profits. EDA strategies, which are similar to targeted advertising in previous research (e.g., Iyer et al., 2005; Zhang et al., 2016) allow manufacturers to reduce advertising costs by focusing on their customer base. Surprisingly, the implementation of the EDA equilibrium intensifies price competition due to its limited market coverage. As a result of their uniform pricing policies, dealers have no choice but to significantly reduce retail prices when manufacturers advertise only to their market base to effectively compete in the entire market.

\section{Integrated channels}

This section investigates the type of advertising activities members of a given symmetric channel should undertake at the equilibrium if they eliminate vertical externalities to maximize their joint profit functions given by:

$$
T_{i}=p_{i} q_{i}-c_{1} O_{i}-c_{2} D_{i}, \quad i=1,2 .
$$

Under the symmetric scenario the profit functions simplify as follows:

$$
T=p q-c_{1} O-c_{2} D .
$$

The problem is reduced to a standard duopoly competition as the two channels are now fully integrated (e.g., Iyer et al., 2005). A Nash game is played between the two integrated channels. As in the case of decentralized channels, we investigate the existence of an interior solution and two corner solutions and 
we are able to analytically characterize the EDA and ODA equilibria and find that the EOA equilibrium is unfeasible (See Appendix B).

The players' strategies and profits for the ODA equilibrium depend on the game parameters, including $n, t, c_{1}, c_{2}, \delta$, and $\theta$. Again, some restrictions need to be imposed on the parameters to satisfy the concavity conditions and obtain non-negative profits, positive price, advertising efforts, and demands as well as to ensure that the sales of the two integrated channels do not exceed the number of potential consumers. On the other hand, the players' strategies and profits for the EDA equilibrium depend exclusively on the parameters $n, t$, and $c_{2}$. In this case, the following condition should be met to ensure that the sales of the two integrated channels do not exceed the number of potential consumers: $t \leq 4 c_{2} / n$.

We display the feasibility conditions of the EDA and ODA equilibria for the same parameter values as those used in the case of decentralized channels in Figures 3a, 3b, and 3c. In particular, $n=1, c_{1}=1$ and $c_{2}=0.25,0.5,0.75$, while $t$ and $\theta$ vary in the following ranges: $t \in(0,4]$ and $\theta \in[0,1]$. Remember, the parameter $\theta$ does not affect the EDA equilibrium. Figures 3a, 3b, and $3 \mathrm{c}$ are plotted for $\delta=\theta$ and are qualitatively similar to those obtained for $\delta=0.5 \theta$ and $\delta=1.5 \theta$.

Similar to the case of decentralized channels, in the upper parts of these figures which correspond to higher transportation costs, neither the EDA equilibrium nor the ODA equilibrium is feasible. The feasibility areas of these two equilibria expand as the defensive advertising costs increase. In addition, the feasibility area of the ODA equilibrium is a subset of the feasibility area of the EDA equilibrium. Stated differently, investments in both offensive and defensive advertising are only possible when the two firms can also choose to exclusively invest in defensive advertising. The reverse is not true. As a result, the EDA equilibrium is the unique equilibrium when offensive advertising is either as effective as defensive advertising or highly effective. Again, advertising is exclusively allocated to a firm's own customer base when the potential of engaging in an offensive advertising war is high.

Given the existence of two equilibria in some areas of the parameter space, the two integrated channels have to determine the equilibrium to be implemented. We compare channel profits under the EDA and the ODA equilibria to identify the best strategy for the two integrated channels. Our findings are stated in the following claim.

Claim 3. Members of an integrated channel prefer the ODA equilibrium to the EDA equilibrium, which is played only when the former is unfeasible.

To better understand this claim, we further compare the strategies of the players for these two equilibria. In addition to the fact that offensive advertising is also undertaken in the ODA equilibrium, this analysis reveals that both the retail price and the defensive advertising of the ODA equilibrium are always greater than those of the EDA equilibrium, i.e.:

$$
p_{\text {Int }}^{O D A}>p_{\text {Int }}^{E D A}, \quad D_{\text {Int }}^{O D A}>D_{\text {Int }}^{E D A}, \quad O_{\text {Int }}^{O D A}>O_{\text {Int }}^{E D A}=0,
$$

where the subscript Int stands for integrated channel. In integrated channels, channel members heavily invest to attack the rival's channel and to protect their customer base and this offers the opportunity to charge higher prices. Thus, consistent with our previous finding, limiting advertising only to one's own customer base reduces advertising expenditures, but also hurts channel profits even when vertical channel externalities are taken out.

To conclude, either the EDA equilibrium or the ODA equilibrium can be implemented in an integrated channel, while the EOA equilibrium, which is synonymous with an advertising war between channels, 

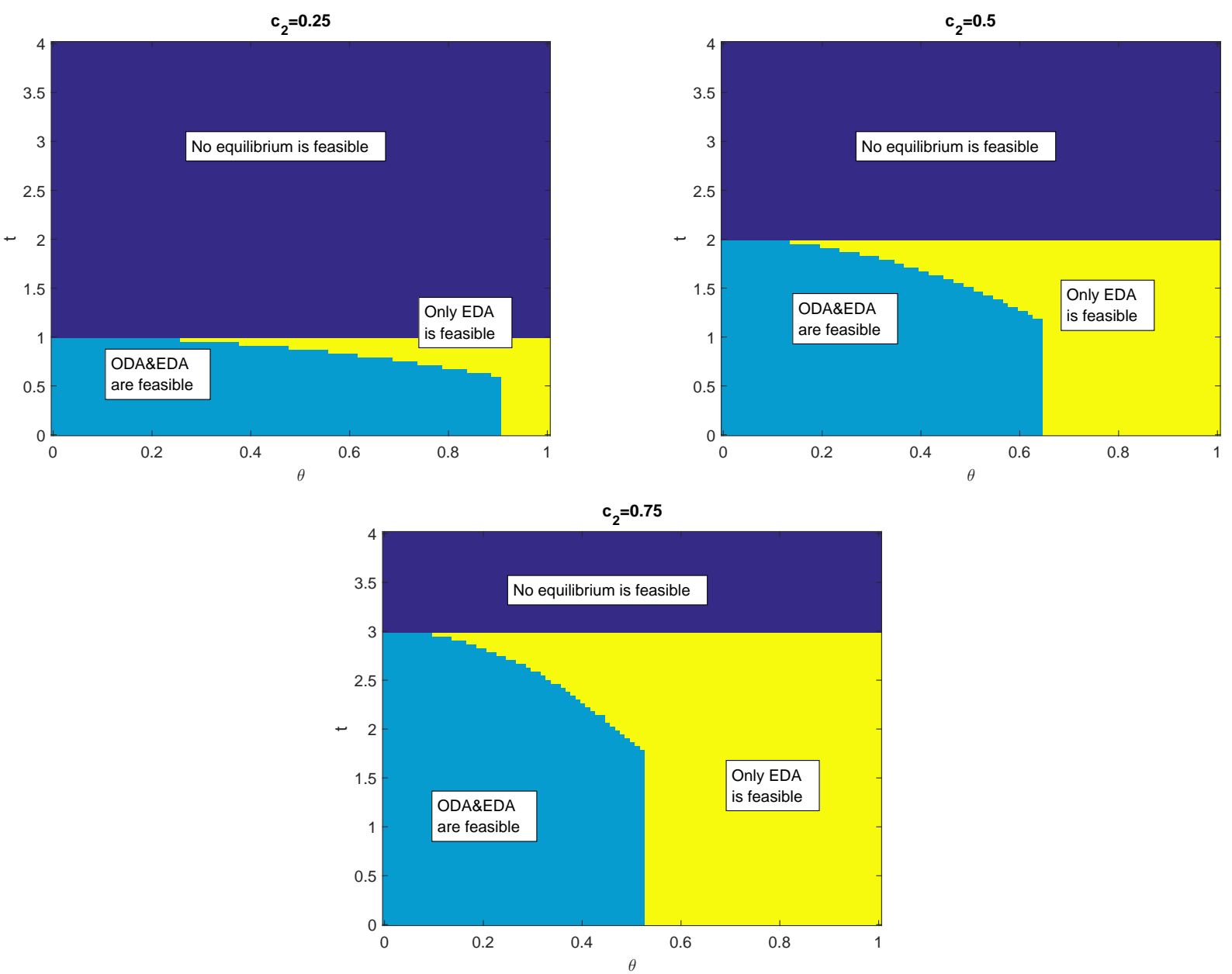

Fig. 3. Feasibility scenario $\delta=\theta$ for different values of $c_{2}$. First line, Figure $3 \mathrm{a} c_{2}=0.25$ left; Figure $3 \mathrm{~b} c_{2}=0.5$ right. Second line, Figure $3 \mathrm{c} c_{2}=0.75$.

is unrealistic.

\section{Decentralized vs. integrated channels}

In this section, we investigate how strategies and profits compare in the integrated and decentralized channels. The different comparisons are made for the same values of the parameters used previously to establish the feasibility regions of the different equilibria. Denoting by $\Pi_{\text {Tint }}=T_{i}$ the total profits of each integrated channel and by $\Pi_{T}=M_{i}+R_{i}$ the total profits of each decentralized channel, we compare $\Pi_{\text {Tint }}$ and $\Pi_{T}$. The following claim summarizes our findings:

Claim 4. (i) For $\delta=0.5 \theta$ and $\delta=\theta$, the total channel profits are always greater in the decentralized 
channels than in the integrated channels regardless of the equilibrium implemented, i.e., $\Pi_{T}>\Pi_{\text {Tint }}$;

(ii) for $\delta=1.5 \theta$, total channel profits of the decentralized and integrated channels compare as follows:

$$
\begin{aligned}
& \Pi_{T}^{O D A}>\Pi_{\text {Tint }}^{O D A}, \quad \Pi_{T}^{E D A}>\Pi_{\text {Tint }}^{O D A}, \quad \Pi_{T}^{O D A}>\Pi_{\text {Tint }}^{E D A}, \quad \Pi_{T}^{E D A}>\Pi_{\text {Tint }}^{E D A}, \\
& \Pi_{T}^{E O A}<\Pi_{\text {Tint }}^{O D A}, \quad \Pi_{T}^{E O A}<\Pi_{\text {Tint }}^{E D A} .
\end{aligned}
$$

The findings in the above claim suggest that, in most areas, the total profits are higher in decentralized channels than in integrated channels when the brands are highly substitutable. This finding is consistent with Zhang et al. (2012) who reached a similar conclusion when competing manufacturers undertake informative advertising. Conversely, the total channel profits are higher when channels are integrated than when they are decentralized in areas where the products are relatively well differentiated and the offensive advertising retaliatory capacity of the rival is stronger, i.e., $\delta=1.5 \theta$. In these areas, the EOA equilibrium is the unique equilibrium of the decentralized channel game, while integrated channels can adopt either the ODA or the EDA equilibria. This implies that integrated channels can better target advertising than decentralized channels when the product are differentiated and the rival is offensively very strong. The latter prefer to engage in offensive advertising rivalry. However, such a move hurts their bottom line.

We further compare the players' strategies to better understand the implications of Claim 4. Given the feasibility conditions, when $\delta=\theta$ or $\delta=0.5 \theta$, we consider four cases: (1) ODA integrated channel vs. ODA decentralized channel, (2) ODA integrated channel vs. EDA decentralized channel, (3) EDA integrated channel vs. ODA decentralized channel, and (4) EDA integrated channel vs. EDA decentralized channel. The results of these comparisons are summarized in the claim below:

Claim 5. If $\delta=\theta$ or $\delta=0.5 \theta$, the players' strategies in integrated and decentralized channels compare as follows:

$$
\begin{array}{lll}
p^{O D A}>p_{i n t}^{O D A}, & D^{O D A}>D_{i n t}^{O D A}, & O^{O D A}<O_{i n t}^{O D A}, \\
p^{E D A}>p_{i n t}^{O D A}, & D^{E D A}>D_{i n t}^{O D A}, & O^{E D A}=0<O_{i n t}^{O D A}, \\
p^{O D A}>p_{i n t}^{E D A}, & D^{O D A}>D_{\text {int }}^{E D A}, & O^{O D A}>O_{i n t}^{E D A}=0, \\
p^{E D A}>p_{i n t}^{E D A}, & D^{E D A}>D_{i n t}^{E D A}, & O^{E D A}=O_{i n t}^{E D A}=0 .
\end{array}
$$

Remember, the above comparisons are only possible when the brands are moderately or highly substitutable. As expected, retail prices of the decentralized channels are higher than those of the integrated channels regardless of the type of advertising programs implemented. This is mostly due to the well-documented double marginalization phenomenon. Defensive advertising expenditures are higher in decentralized channels than in integrated channels, which means that decentralization allows channel members to further focus advertising efforts on their respective customer base. On the other hand, except when offensive marketing is not conducted in either decentralized channels or in integrated channels, integrated channels invest more in offensive advertising than decentralized channels. These findings are in line with the "retailer-buffer" role as offensive advertising is intended (and defensive advertising is not intended) to increase the rivalry between the two channels.

On the other hand, $\delta=1.5 \theta$, given the feasibility conditions, six cases are considered: (1) ODA integrated channel vs. ODA decentralized channel, (2) ODA integrated channel vs. EDA decentralized channel, (3) ODA integrated channel vs. EOA decentralized channel, (4) EDA integrated channel vs. 
ODA decentralized channel, (5) EDA integrated channel vs. EDA decentralized channel, and (6) EDA integrated channel vs. EOA decentralized channel. The results of the comparisons are as follows:

Claim 6. If $\delta=1.5 \theta$, the players' strategies in integrated and decentralized channels compare as follows:

$$
\begin{array}{lll}
p^{O D A}>p_{i n t}^{O D A}, & D^{O D A}>D_{i n t}^{O D A}, & O^{O D A}<O_{i n t}^{O D A}, \\
p^{E D A}>p_{i n t}^{O D A}, & D^{E D A}>D_{i n t}^{O D A}, & O^{E D A}=0<O_{i n t}^{O D A}, \\
p^{O D A}>p_{i n t}^{E D A}, & D^{O D A}>D_{\text {int }}^{E D A}, & O^{O D A}>O_{i n t}^{E D A}=0, \\
p^{E D A}>p_{i n t}^{E D A}, & D^{E D A}>D_{i n t}^{E D A}, & O^{E D A}=O_{i n t}^{E D A}=0, \\
p^{E O A}<p_{i n t}^{E D A}, & D^{E O A}=0<D_{i n t}^{E D A}, & O^{E O A}>O_{i n t}^{E D A}=0 . \\
p^{E O A}<p_{i n t}^{O D A}, & D^{E O A}=0<D_{i n t}^{O D A}, & O^{E O A}<O_{i n t}^{O D A},
\end{array}
$$

Observe that the findings of Claim 5 obtained for $\delta=\theta$ or $\delta=0.5 \theta$ are qualitatively identical to those of Claim 6 when the feasible equilibria are the same, i.e., decentralized channels' prices and defensive advertising expenditures are higher, while their offensive advertising expenditures are lower compared to those of the integrated channels, except when the corresponding strategy is set to zero in either case. New in Claim 6 are the comparisons that involve the EOA equilibrium in decentralized channels. As previously discussed, this equilibrium is only implemented when the brands are highly differentiated and the retaliatory capacity of the rival is stronger. Surprisingly, channel decentralization leads to lower prices and offensive advertising expenditures compared to channel integration. In corresponding areas, integrated channel members either invest exclusively in defensive advertising or combine offensive and defensive advertising to maintain higher prices and avoid a wasteful offensive advertising competition between channels.

Summarizing, channel decentralization leads to higher prices and defensive advertising expenditures, lower offensive advertising expenditures, and higher profits than channel integration when the products are moderately or highly substitutable. Conversely, it produces lower profits and prices, nullifies defensive advertising activities, and may conduct to higher or lower offensive marketing activities, depending on the equilibria being compared, when the products are highly differentiated and the retaliatory capacity of the rival is stronger.

\section{Conclusion}

This paper has investigated pricing and advertising competition between two exclusive channels that serve two market segments. Consumers naturally prefer to purchase from one channel, but can purchase from either channel depending on manufacturers' marketing efforts. A manufacturer has the possibility to undertake defensive and/or offensive advertising to protect their own market base and/or attack the rival's market base, respectively. The questions addressed in this paper are: Should manufacturers, in both decentralized and integrated channels, exclusively direct their advertising efforts either to their own customer base or the rival's customer base, or should they simultaneously advertise to the two market segments at the equilibrium? What should the optimal channel structure be if channel members act so as to maximize total channel profits? A game theoretic model that allows these two questions to be addressed was developed and analyzed. Three equilibria were characterized in the context of decentralized channels, namely the EOA (Exclusive Offensive Advertising), EDA (Exclusive Defensive Advertising), 
and ODA equilibria (Offensive-Defensive Advertising) and two equilibria were obtained for integrated channels, including the EDA and ODA equilibria.

In response to the first question, we found that decentralized channels can implement any one of the three equilibria depending on their feasibility conditions. In particular, when multiple equilibria exist, the ODA equilibrium is preferred to the EDA equilibrium, which itself is preferred to the EOA equilibrium. The EOA equilibrium should only be implemented when it is unique. This occurs only when the products are highly differentiated and the offensive advertising retaliatory capacity of the rival is stronger. On the other hand, integrated channels prefer the ODA equilibrium to the EDA equilibrium, which is only implemented when it is unique. Regardless of the level of differentiation between brands, the EOA equilibrium is not feasible. Therefore, the selection of an advertising targeting strategy depends, among others, on vertical channel interactions between channel members, the level of differentiation between competitive products, and the relative offensive advertising capacity of the competitors.

In response to the second question, we found that total channel profits are higher in decentralized channels and lower in integrated channels when the brands are moderately or highly substitutable. Conversely, total channel profits of integrated channels are higher than those of decentralized channels in areas where the products are relatively differentiated and the offensive advertising retaliatory capacity of the rival is stronger. Under these conditions, decentralized channels implement the EOA equilibrium, while integrated channels adopt either the ODA equilibrium or the EDA equilibrium.

The findings of this research make two major contributions to the literature. First, they demonstrate that, whether competing channels are decentralized or integrated, they can properly target their advertising decisions to adapt to their market conditions. Despite the cost saving argument used to support focusing advertising on a firm's own customer base in the current literature (e.g., Iyer et al., 2005; Zhang et al., 2016), manufacturers of substitutable products can be better off when they implement a full differentiated advertising program that appeals specifically to each of the two market segments. This option is not the least expensive, but it provides better market coverage and drives the prices and profits up. Alternatively, advertising exclusively to a firm's own customer base, as suggested in the literature, is still strategically possible depending on several factors, including the transportation cost, the relative effectiveness of offensive advertising, and the relative intensity of the rival's offensive advertising retaliatory capacity. On the other hand, in decentralized channels, exclusively targeting the rival's market base could be an optimal strategic option as well, especially when the products are relatively differentiated. A manufacturer can target the competitor's customer base in anticipation of future advertising assaults from a more powerful rival. This type of preemptive attack is less likely to lead to a suicidal advertising war due to its limited scope and impact on the rival when the products are relatively well differentiated (Steenkamp et al., 2005). As a result, the two manufacturers see no need to defend their own customer bases. Traditional Lanchester-type models consider similar advertising strategies, although they overlook vertical interactions and customers' preferences, among others.

Second, the findings of this research are consistent with the "retailer-buffer" explanation advanced by McGuire and Stealin (1983). In particular, they support the view that total channel profits are higher in decentralized than in integrated channels when products are moderately or highly substitutable. Zhang et al. (2012) reached a similar conclusion when competing manufacturers undertake informative advertising. In this work, advertising, whether offensive or defensive, could be considered as informative as it does not aim at changing consumers' preferences by increasing transportation costs. In addition to attenuating price competition between highly substitutable products, we found that decentralization 
leads to lower offensive and higher defensive advertising investments, unless the corresponding type of advertising in either centralized or decentralized channels is set to zero. Put differently, manufacturers' advertising investments may either increase or decrease with decentralization when products are highly substitutable depending on whether they are primarily targeted to their own customer base or to the rival's customer base.

We have simplified this model with several assumptions to allow us to derive meaningful insights. Some of these assumptions limit the generalizability of our findings. For instance, we have considered that whether advertising is offensive or defensive, it does not directly change customer preference for any of the two brands. This is consistent with the view that advertising is mainly informative (e.g., Zhang et al., 2012). Therefore, our findings may not apply to cases where advertising is persuasive. Given the multiplicative structure of our demand functions, allowing advertising to directly influence consumers' preferences makes it very difficult to derive analytical solutions for the different advertising scenarios we wanted to study in this research. Also, we have considered in this study that retailers set an identical price for the two market segments to focus exclusively on advertising strategies. Full differentiated strategies that combine both targeted pricing and advertising decisions simultaneously could also be investigated (e.g., Iyer et al, 2005; Zhang et al., 2016). Finally, this work could also be extended to integrate local advertising at the retail level. This will add another layer of difficulties given that channel members may not agree on the type of advertising to conduct, on top of the traditional vertical free-riding issue in such a context (Martín-Herrán and Sigué, 2017).

\section{Acknowledgments}

The first author acknowledges financial support from the Spanish Government under research project ECO2017-82227-P, as well as financial aid from Junta de Castilla y León VA024P17 and VA105G18, co-financed by FEDER funds.

\section{References}

Coughlan, A.T., 1985. Competition and cooperation in marketing channel choice: Theory and applications. Marketing Science 4, 110-129.

Erickson, G.M., 1993. Offensive and defensive marketing: closed-loop duopoly strategies. Marketing Letters 4(4), $285-295$.

Hotelling, H., 1929. Stability in competition. Economic Journal 39, 41-57.

Huang, J., Leng, M., Liang, L., 2012. Recent developments in dynamic advertising research. European Journal of Operational Research 220, 591-609.

Ingene, C.A., Taboubi, S., Zaccour, G., 2012. Game-theoretic coordination mechanisms in distribution channels: Integration and extensions for models without competition. Journal of Retailing 88(4), 476-496.

Iyer, G., Soberman, D., Villas-Boas, J.M., 2005. The targeting of advertising. Marketing Science 24(3), 461-476.

Karray, S., 2013. Periodicity of pricing and marketing efforts in a distribution channel. European Journal of Operational Research 228(3), 635-647.

Karray, S., Martín-Herrán, G., Zaccour, G., 2017. Assessing the profitability of cooperative advertising programs in competing channels. International Journal of Production Economics 187, 142-158.

McGuire, T., Staelin, R., 1983. An industry equilibrium analysis of downstream vertical integration. Marketing Science 2, $161-192$.

Martín-Herrán, G., McQuitty, S., Sigué, S. P., 2012. Offensive versus defensive marketing: What is the optimal spending allocation? Interna-

tional Journal of Research in Marketing 29, 210-219. 
Martín-Herrán, G., Sigué, S.P., 2018. Offensive and defensive marketing in spatial competition. Journal of Service Research. Doi.org/10.1177/1094670518819853.

Martín-Herrán, G., Sigué, S.P., 2017. Retailer and manufacturer advertising scheduling in a channel. Journal of Business Research 78, 93-100. Moorthy, K.S., 1988. Strategic decentralization in channels. Marketing Science 7, 335-355.

Shaffer, G., Zettelmeyer, F., 2004. Advertising in a distribution channel. Marketing Science 23(4), 619-628.

Shaffer, G., Zettelmeyer, F., 2009. Comparative advertising and in-store displays. Marketing Science 28(6), 114-1156.

Steenkamp, J-B.E., Nijs, V.R., Hassens, D.M., Dekimpe, M., 2005. Competitive reactions to advertising and promotion attacks. Marketing Science 24(1), 35-54.

Trivedi, M., 1998. Distribution channels: An extension of exclusive retailership. Management Science 48(7), 896-909.

Wang, C.-J., Chen, Y.-J., Wu, C.-C., 2011. Advertising competition and industry channel structure. Marketing Letters 22, 79-99.

Wu, C.-C., Chen, Y.-J., Wang, C.-J., 2009. Is persuasive advertising always combative in a distribution channel? Marketing Science 28(6), 1157-1163.

Zhang, J., Liu, Z., Zhong, W., 2016. Attack and defend; the role of targeting in a distribution channel. Marketing Letters 27, $375-386$.

Zhang, J., Zhong, W., Mei, S., 2012. Competitive effects of informative advertising in distribution channels. Marketing Letters 23 , 561-584.

\section{Appendix A: Decentralized channels}

For the decentralized channels we can analytically characterize the two corner equilibria ( $E O A$ and $E D A)$. However, the interior equilibrium $O D A$ cannot be fully analytically characterized except in the scenario where $\delta=\theta$.

\section{A.1. Interior equilibrium: OD A equilibrium}

First we focus on the characterization of interior equilibria.

The retailers are the followers in the Stackelberg game and play a game between them à la Nash.

Retailer $i$ 's objective function after the expression of the demand function has been replaced reads:

$$
R_{i}=\frac{n}{2 t}\left(p_{i}-w_{i}\right)\left(\sqrt{D_{i}}\left(-p_{i}+p_{j}+t\right)+\sqrt{O_{j}}\left(p_{i}-p_{j}-t\right) \delta+\sqrt{O_{i}}\left(p_{i}-p_{j}+t\right) \theta\right), i, j=1,2, i \neq j .
$$

The derivative with respect to $p_{i}$ is:

$$
\frac{n}{2 t}\left(\sqrt{D_{i}}\left(-2 p_{i}+p_{j}+t+w_{i}\right)+\sqrt{O_{j}}\left(2 p_{i}-p_{j}-t-w_{i}\right) \delta+\sqrt{O_{i}}\left(2 p_{i}-p_{j}+t-w_{i}\right) \theta\right) .
$$

From the first-order optimality conditions for an interior solution, we obtain the retailers' reaction functions:

$$
p_{i}\left(w_{i}, w_{j}, O_{i}, O_{j}, D_{i}, D_{j}\right)=\frac{N u m p_{i}}{\operatorname{Denp}_{i}}
$$


where

$$
\begin{aligned}
\text { Nump }_{i} & =\left(3 t+2 w_{i}+w_{j}\right)\left(\sqrt{D_{j}} \sqrt{O_{j}} \delta+\sqrt{D_{i}}\left(-\sqrt{D_{j}}+\sqrt{O_{i}} \delta\right)\right) \\
& -\sqrt{O_{i}}\left(t-2 w_{i}-w_{j}\right)\left(\sqrt{D_{j}}-\sqrt{O_{i}} \delta\right) \theta+\sqrt{O_{j}}\left(t+2 w_{i}+w_{j}\right)\left(\sqrt{D_{i}}-\sqrt{O_{j}} \delta\right) \theta \\
& -\sqrt{O_{i}} \sqrt{O_{j}}\left(3 t\left(\delta^{2}-\theta^{2}\right)+\left(2 w_{i}+w_{j}\right)\left(\delta^{2}+\theta^{2}\right)\right), \\
\text { Denp }_{i} & =3\left(\sqrt{D_{i}}-\sqrt{O_{j}} \delta-\sqrt{O_{i}} \theta\right)\left(-\sqrt{D_{j}}+\sqrt{O_{i}} \delta+\sqrt{O_{j}} \theta\right) .
\end{aligned}
$$

Manufacturers $i$ 's objective function after the expressions of the retailers' reaction functions have been replaced reads:

$$
M_{i}=\frac{N u m M_{i}}{\operatorname{Den} M_{i}},
$$

where

$$
\begin{aligned}
\operatorname{NumM}_{i} & =6 O_{i}^{3 / 2} c_{1} t \delta+n w_{i}\left(3 t-w_{i}+w_{j}\right)\left(-\sqrt{D_{j}} \sqrt{O_{j}} \delta+\sqrt{D_{i}}\left(-\sqrt{D_{j}}+\sqrt{O_{i}} \delta\right)\right. \\
& +\sqrt{O_{i}} n w_{i}\left(t+w_{i}-w_{j}\right)\left(\sqrt{D_{j}}-\sqrt{O_{i}} \delta\right)+\sqrt{O_{j}} n w_{i}\left(t-w_{i}+w_{j}\right)\left(-\sqrt{D_{i}}+\sqrt{O_{j}} \delta\right) \theta \\
& +\sqrt{O_{i}}\left(6 D_{j} c_{2} t \delta+\sqrt{O_{j}} n w_{i}\left(3 t\left(\delta^{2}-\theta^{2}\right)-\left(w_{i}-w_{j}\right)\left(\delta^{2}+\theta^{2}\right)\right)\right) \\
& -6 t\left(\sqrt{D_{j}}-\sqrt{O_{j}} \theta\right)\left(O_{i} c_{1}+D_{i} c_{2}\right), \\
\operatorname{DenM}_{i} & =6 t\left(\sqrt{D_{j}}-\sqrt{O_{i}} \delta-\sqrt{O_{j}} \theta\right) .
\end{aligned}
$$

The derivative with respect to $w_{i}, O_{i}$ and $D_{i}$ are:

$$
\begin{aligned}
& \frac{n}{\operatorname{DenM}_{i}} \Delta_{w_{i}}, \\
& \frac{1}{12 \sqrt{O_{i}} t\left(\sqrt{D_{j}}-\sqrt{O_{i}} \delta-\sqrt{O_{j}} \theta\right)^{2}} \Delta_{O_{i}}, \\
& \frac{1}{12 \sqrt{D_{i}} t\left(\sqrt{D_{j}}-\sqrt{O_{i}} \delta-\sqrt{O_{j}} \theta\right)} \Delta_{D_{i}},
\end{aligned}
$$

where

$$
\begin{aligned}
\Delta_{w_{i}}= & \sqrt{O_{i}}\left[\left(t+2 w_{i}-w_{j}\right)\left(\sqrt{D_{j}}-\sqrt{O_{i}} \delta\right) \theta+\sqrt{O_{j}}\left(3 t\left(\delta^{2}-\theta^{2}\right)-\left(2 w_{i}-w_{j}\right)\left(\delta^{2}+\theta^{2}\right)\right)\right]+ \\
& \left(3 t-2 w_{i}+w_{j}\right)\left(-\sqrt{O_{j}} \sqrt{D_{j}} \delta+\sqrt{D_{i}}\left(\sqrt{D_{j}}-\sqrt{O_{i}} \delta\right)-\sqrt{O_{j}}\left(t-2 w_{i}+w_{j}\right)\left(\sqrt{D_{i}}-\sqrt{O_{j}} \delta\right) \theta,\right. \\
\Delta_{O_{i}}= & -12 O_{i}^{3 / 2} c_{1} t \delta^{2}+O_{i} \delta\left[24 \sqrt{D_{j}} c_{1} t+\left(-24 \sqrt{O_{j}} c_{1} t+n w_{i}\left(t+w_{i}-w_{j}\right) \delta\right) \theta\right]- \\
& 2 \sqrt{O_{i}}\left(\sqrt{D_{j}}-\sqrt{O_{j}} \theta\right)\left[6 \sqrt{D_{j}} c_{1} t+\left(-6 \sqrt{O_{j}} c_{1} t+n w_{i}\left(t+w_{i}-w_{j}\right) \delta\right) \theta\right]+ \\
& n w_{i} \theta\left[D_{j}\left(t+w_{i}-w_{j}\right)+2 \sqrt{O_{j}} \sqrt{D_{i}} t \delta-2 \sqrt{O_{j}} \sqrt{D_{j}}\left(2 t+w_{i}-w_{j}\right) \theta+O_{j}\left(\left(w_{i}-w_{j}\right) \theta^{2}+t\left(3 \theta^{2}-2 \delta^{2}\right)\right)\right], \\
\Delta_{D_{i}}= & n w_{i}\left[\left(3 t-w_{i}+w_{j}\right)\left(\sqrt{D_{j}}-\sqrt{O_{j}} \delta\right)-\sqrt{O_{j}}\left(t-w_{i}+w_{j}\right) \theta\right]- \\
& 12 \sqrt{D_{i}} c_{2} t\left(\sqrt{D_{j}}-\sqrt{O_{i}} \delta-\sqrt{O_{j}} \theta\right) .
\end{aligned}
$$


$i, j=1,2, i \neq j$.

Equating the above expressions to zero, we get the first-order optimality conditions for an interior equilibrium, and looking for a symmetric solution $w_{1}=w_{2}=w, O_{1}=O_{2}=O, D_{1}=D_{2}=D$, these conditions simplify as follows:

$$
\begin{aligned}
(3 t-w) \sqrt{D}+\sqrt{O}((\delta+\theta) w-(\delta-\theta) 3 t) & =0, \\
-\sqrt{D} n w \theta-12 O c_{1}(\delta+\theta)+\sqrt{O}\left(12 c_{1} \sqrt{D}+n w \theta(3 \theta-\delta)\right) & =0, \\
-12 c_{2} D-\sqrt{O} n w(3 \delta+\theta)+3 \sqrt{D}\left(n w+4 \sqrt{O} c_{2}(\delta+\theta)\right) & =0 .
\end{aligned}
$$

From (A1) we get $w$ as a function of $D$ and $O$ :

$$
w=\frac{3 t(\sqrt{D}+\sqrt{O}(\theta-\delta))}{\sqrt{D}-\sqrt{O}(\delta+\theta)} .
$$

Replacing this last expression in (A2) and (A3) we have:

$$
\begin{aligned}
& -D n t \theta+4 O^{3 / 2} c_{1}(\delta+\theta)^{2}+2 \sqrt{O}\left(2 D c_{1}+\sqrt{D} n t \theta^{2}\right)+O\left(n t(\delta-3 \theta)(\delta-\theta) \theta-8 \sqrt{D} c_{1}(\delta+\theta)\right)=0 \\
& 4 D^{3 / 2} c_{2}-O n t(\delta-\theta)(3 \delta+\theta)-D\left(3 n t+8 \sqrt{O} c_{2}(\delta+\theta)\right)+\sqrt{D}\left(2 \sqrt{O} n t(3 \delta-\theta)+4 O c_{2}(\delta+\theta)^{2}\right)=0
\end{aligned}
$$

This system of two nonlinear equations cannot be analytically solved, in general. For the numerical illustrations presented in the body of the manuscript we have numerically solved this system.

The second-order concavity conditions ensuring an interior maximum for the symmetric solution $(w, O, D)$ read:

$$
\begin{aligned}
& -\sqrt{D}+(\theta+\delta) \sqrt{O}<0 \\
& -2 D^{3 / 2} t w+\sqrt{O} D\left(\left(t^{2}+w^{2}\right) \theta+2 t w(\delta+6 \theta)\right)+2 O \sqrt{D}\left(t^{2}(\delta-3 \theta) \theta-w^{2} \theta(\delta+\theta)+t w\left(5 \delta^{2}-10 \delta \theta-11 \theta^{2}\right)\right) \\
& \quad+O^{3 / 2}\left(t^{2}(\delta-3 \theta)^{2} \theta+w^{2} \theta(\delta+\theta)^{2}-2 t w\left(5 \delta^{3}-11 \delta \theta^{2}-6 \theta^{3}\right)\right)<0 \\
& -D^{2}\left(9 t^{2}-12 t w+w^{2}\right)+\sqrt{O} D^{3 / 2}\left(w^{2}(\delta+2 \theta)+t^{2}(9 \delta+30 \theta)-2 t w(9 \delta+32 \theta)\right) \\
& \quad+D O\left(15 t^{2} \delta(3 \delta-7 \theta)+w^{2} \delta(5 \delta+3 \theta)-2 t w\left(27 \delta^{2}-75 \delta \theta-52 \theta^{2}\right)\right) \\
& \quad+O^{2}(3 \delta+\theta)\left(t^{2}(\delta-3 \theta)^{2} \theta+w^{2} \theta(\delta+\theta)^{2}-2 t w\left(5 \delta^{3}-11 \delta \theta^{2}-6 \theta^{3}\right)\right) \\
& \quad-O^{3 / 2} \sqrt{D}\left(w^{2}(\delta+\theta)^{2}(5 \delta+2 \theta)+5 t^{2}\left(9 \delta^{3}-12 \delta^{2} \theta-7 \delta \theta^{2}+6 \theta^{3}\right)-2 t w\left(45 \delta^{2}-34 \delta^{2} \theta-95 \delta \theta^{2}-32 \theta^{3}\right)\right)>0 .
\end{aligned}
$$

\section{A.1.1. Case $\theta=\delta$}

For the case $\theta=\delta$, system (A4)-(A5) that characterizes the interior equilibria simplifies as follows:

$$
\begin{aligned}
\left(4 c_{2} \sqrt{D}-3 n t\right)(\sqrt{D}-2 \sqrt{O} \delta)^{2}+4 \sqrt{O} n t \delta(3 \sqrt{O} \delta-2 \sqrt{D}) & =0 \\
(\sqrt{D}-2 \sqrt{O} \delta)\left(4 \sqrt{D} \sqrt{O} c_{1}-8 O c_{1} \delta-\sqrt{D} n t \delta\right) & =0 .
\end{aligned}
$$

From the second equation two options are possible. The first option establishes $\sqrt{D}=2 \sqrt{O} \delta$. Replacing this value into the first equation, this last equations reads: $-4 O n t \delta^{2}=0$, and then, $O=0$, and $D=0$. Therefore, this first possibility should be removed because we are characterizing interior equilibria. 
The second option establishes $4 \sqrt{D} \sqrt{O} c_{1}-8 O c_{1} \delta-\sqrt{D} n t \delta=0$. Solving for $\sqrt{D}$ we get:

$$
\sqrt{D}=\frac{8 O c_{1} \delta}{4 \sqrt{O} c_{1}-n t \delta}
$$

Replacing into the first equation and simplifying, this last equation reads:

$$
-32 O^{3 / 2} c_{1} n t \delta^{2}\left(8 O c_{1}^{2}-n^{2} t^{2} \delta^{2}+2 \sqrt{O} n t \delta\left(c_{1}-2 c_{2} \delta^{2}\right)\right)=0 .
$$

Taking into account that we are characterizing interior equilibria, this equation implies:

$$
8 O c_{1}^{2}-n^{2} t^{2} \delta^{2}+2 \sqrt{O} n t \delta\left(c_{1}-2 c_{2} \delta^{2}\right)=0 .
$$

Solving for $\sqrt{O}$ two possible expressions can be derived, but only one is positive and given by:

$$
\sqrt{O}=\frac{n t \delta\left(-c_{1}+2 c_{2} \delta^{2}+\sqrt{8 c_{1}^{2}+\left(2 c_{2} \delta^{2}-c_{1}\right)^{2}}\right)}{8 c_{1}^{2}} .
$$

Replacing this value into (A6), the final expression of $\sqrt{D}$ is:

$$
\sqrt{D}=\frac{-n t \delta^{2}\left(-c_{1}+2 c_{2} \delta^{2}+\sqrt{8 c_{1}^{2}+\left(2 c_{2} \delta^{2}-c_{1}\right)^{2}}\right)^{2}}{4 c_{1}^{2}\left(3 c_{1}-2 c_{2} \delta^{2}-\sqrt{8 c_{1}^{2}+\left(2 c_{2} \delta^{2}-c_{1}\right)^{2}}\right)} .
$$

It can be easily proved that $\sqrt{D}>0$ for any value of $c_{1}, c_{2}, \delta$ and $t$.

\section{A.2. Corner equilibrium $(O=0)$ : EDA equilibrium}

Replacing $O=0$ in (A1) and (A3), and solving this system of two equations, one gets the manufacturers' optimal strategies in the EDA equilibrium:

$$
w^{E D A}=3 t, \quad O^{E D A}=0, \quad D^{E D A}=\frac{9 n^{2} t^{2}}{16 c_{2}^{2}} .
$$

The retailers' optimal strategies in the EDA equilibrium read

$$
p^{E D A}=4 t .
$$

It can be easily proved that the retailers' profit function is strictly concave with respect to the decision variable (i.e. the retail price).

The optimal demand, manufacturers' profits and retailers' profits read:

$$
q^{E D A}=\frac{3 n^{2} t}{8 c_{2}}, \quad M^{E D A}=\frac{9 n^{2} t^{2}}{16 c_{2}}, \quad R^{E D A}=\frac{3 n^{2} t^{2}}{8 c_{2}} .
$$


The condition on the total demand $q_{1}+q_{2} \leq n$, taking into account $q^{E D A}$ establishes $3 n t-4 c_{2} \leq 0$. This last condition can be rewritten as: $t \leq 4 c_{2} /(3 n)$.

\section{A.3. Corner equilibrium $(O=0)$ : EDA equilibrium}

Replacing $D=0$ in (A1) and (A2), and solving this system of two equations one gets the manufacturers' optimal strategies in the EOA equilibrium:

$$
w^{E O A}=\frac{3 t(\delta-\theta)}{\delta+\theta}, \quad O^{E O A}=\left(\frac{n t(\delta-3 \theta)(\delta-\theta) \theta}{4 c_{1}(\delta+\theta)^{2}}\right)^{2}, \quad D^{E O A}=0 .
$$

A positive wholesale price $w^{E O A}$ requires $\delta-\theta>0$.

The retailers' optimal strategies in the EOA equilibrium read:

$$
p^{E O A}=\frac{4 t(\delta-\theta)}{\delta+\theta} .
$$

It can be easily proved that the retailers' profit function is strictly concave with respect to the decision variable (i.e. the retail price) if and only if $(\delta-\theta)(\delta-3 \theta)<0$. Taking into account the condition that ensures the positivity of $w^{E O A}$, the last condition simplifies as

$$
\delta-3 \theta<0 .
$$

The optimal demand, manufacturers' profits and retailers' profits read:

$$
\begin{aligned}
q^{E O A} & =\frac{n^{2} t \theta(\delta-\theta)^{2}(3 \theta-\delta)}{8 c_{1}(\delta+\theta)^{2}}, \\
M^{E O A} & =\frac{n^{2} t^{2} \theta(\delta-\theta)^{2}(3 \theta-\delta)\left(6 \delta^{2}+\delta \theta-9 \theta^{2}\right)}{16 c_{1}(\delta+\theta)^{4}}, \\
R^{E O A} & =\frac{n^{2} t^{2} \theta(\delta-\theta)^{3}(3 \theta-\delta)}{8 c_{1}(\delta+\theta)^{3}} .
\end{aligned}
$$

Under condition (A7) the optimal demand, manufacturers' profits and retailers' profits are ensured to be positive if the following condition applies:

$$
6 \delta^{2}+\delta \theta-9 \theta^{2}>0
$$

This last condition can be rewritten as follows

$$
\delta>\frac{1}{12}-1 \theta,
$$

or equivalently, $\delta>1.144243 \theta$.

The condition on the total demand $q_{1}+q_{2} \leq n$, taking into account $q^{E O A}$ reads:

$$
n t(\delta-\theta)^{2}(3 \theta-\delta) \theta-4 c_{1}(\delta+\theta)^{2} \leq 0 .
$$


This last condition, taking into account (A7), can be rewritten as: $t \leq 4 c_{1}(\delta+\theta)^{2} /\left(n(\delta-\theta)^{2}(3 \theta-\delta) \theta\right.$.

\section{Appendix B: Integrated channels}

For the integrated channels we can analytically characterize the interior $(O D A)$ and corner equilibria (EOA and $E D A)$.

\section{B.1. Interior equilibrium: $O D M$ equilibrium}

Integrated channel $i$ 's objective function, after the expression of the demand function has been replaced, reads:

$$
T_{i}=\frac{n p_{i}}{2 t}\left(\sqrt{D_{i}}\left(-p_{i}+p_{j}+t\right)+\sqrt{O_{j}}\left(p_{i}-p_{j}-t\right) \delta+\sqrt{O_{i}}\left(p_{i}-p_{j}+t\right) \theta\right)-c_{1} O_{i}-c_{2} D_{i},
$$

$i, j=1,2, i \neq j$.

The derivatives with respect to $p_{i}, O_{i}$ and $D_{i}$ are:

$$
\begin{aligned}
& \frac{n}{2 t}\left(\sqrt{D_{i}}\left(-2 p_{i}+p_{j}+t\right)+\sqrt{O_{j}}\left(2 p_{i}-p_{j}-t\right) \delta+\sqrt{O_{i}}\left(2 p_{i}-p_{j}+t\right) \theta\right), \\
& \frac{n p_{i}\left(p_{i}-p_{j}+t\right)}{4 t \sqrt{O_{i}}}-c_{1} \\
& \frac{n p_{i}\left(-p_{i}+p_{j}+t\right)}{4 t \sqrt{D_{i}}}-c_{2} .
\end{aligned}
$$

Equating the above expressions to zero, we get the first-order optimality conditions for an interior equilibrium, and looking for a symmetric solution $p_{1}=p_{2}=p, O_{1}=O_{2}=O, D_{1}=D_{2}=D$, these conditions simplify as follows:

$$
\begin{aligned}
\frac{n}{t}(\sqrt{D}(-p+t)+\sqrt{O}(p-t) \delta+\sqrt{O}(p+t) \theta) & =0, \\
\frac{n p \theta}{4 \sqrt{O}}-c_{1} & =0, \\
\frac{n p}{4 \sqrt{D}}-c_{2} & =0 .
\end{aligned}
$$

Solving these equations, we obtain the equilibrium strategies:

$$
\begin{aligned}
p_{\text {int }}^{\text {ODA }} & =\frac{t\left(c_{1}+c_{2} \theta(\theta-\delta)\right)}{c_{1}-c_{2} \theta(\delta+\theta)}, \\
O_{\text {int }}^{O D A} & =\left(\frac{n t \theta\left(c_{1}+c_{2} \theta(\theta-\delta)\right)}{4 c_{1}\left(c_{1}-c_{2} \theta(\delta+\theta)\right)}\right)^{2}, \\
D_{\text {int }}^{O D A} & =\left(\frac{n t\left(c_{1}+c_{2} \theta(\theta-\delta)\right)}{4 c_{2}\left(c_{1}-c_{2} \theta(\delta+\theta)\right)}\right)^{2} .
\end{aligned}
$$


A positive equilibrium price requires the following condition:

$$
\frac{c_{1}+c_{2} \theta(\theta-\delta)}{c_{1}-c_{2} \theta(\delta+\theta)}>0
$$

The second-order concavity conditions, ensuring an interior maximum for the symmetric solution $(p, O, D)$, read:

$$
\begin{aligned}
& -\sqrt{D}+\sqrt{O}(\delta+\theta)<0 \\
& -2 \sqrt{D} p t+\sqrt{O}\left(\left(p^{2}+t^{2}\right) \theta+2 p t(\delta+2 \theta)\right)<0, \\
& \sqrt{D}\left(p^{2}-4 p t+t^{2}\right)+\sqrt{O}\left(\left(p^{2}+t^{2}\right) \theta+2 p t(\delta+2 \theta)\right)<0 .
\end{aligned}
$$

The above inequalities under condition (B4) simplify as follows:

$$
\begin{aligned}
& -1+\delta \theta+\theta^{2}<0, \\
& c_{2}^{2} \theta^{4}\left(-1+\delta \theta+\theta^{2}\right)-\left(c_{1}-c_{2} \delta \theta\right)^{2}(-1+\theta(\delta+3 \theta))>0, \\
& c_{2}^{2} \theta^{4}\left(-3+\delta \theta+\theta^{2}\right)-\left(c_{1}-c_{2} \delta \theta\right)^{2}(-1+\theta(\delta+3 \theta))>0 .
\end{aligned}
$$

Demands and total channels' profits at equilibrium read:

$$
\begin{aligned}
q_{i n t}^{O D A} & =\frac{n^{2} t\left(c_{1}+c_{2} \theta(\theta-\delta)\right)^{2}}{8 c_{1} c_{2}\left(c_{1}-c_{2} \theta(\delta+\theta)\right)} \\
T_{i n t}^{O D A} & =\frac{n^{2} t^{2}\left(c_{1}+c_{2} \theta(\theta-2 \delta)\right)\left(c_{1}+c_{2} \theta(\theta-\delta)\right)^{2}}{16 c_{1} c_{2}\left(c_{1}-c_{2} \theta(\delta+\theta)\right)^{2}}
\end{aligned}
$$

The following conditions need to be imposed on the parameters to obtain non-negative profits, positive price and demands, as well as to ensure that the sales of the two firms do not exceed the number of potential consumers:

$$
\begin{aligned}
& c_{1}-c_{2} \theta(\delta+\theta)>0, \\
& c_{1}-c_{2} \theta(2 \delta-\theta)>0, \\
& \frac{n t\left(c_{1}-c_{2} \theta(\delta-\theta)\right)^{2}}{4 c_{1} c_{2}\left(c_{1}-c_{2} \theta(\delta+\theta)\right)} \leq 1 .
\end{aligned}
$$

\section{B.2. Boundary equilibrium $(O=0)$ : EDA equilibrium}

Replacing $O=0$ in (B1) and (B3), and solving this system of two equations, one gets the integrated channel optimal strategies in the EDA equilibrium:

$$
p_{i n t}^{E D A}=t, \quad O_{i n t}^{E D A}=0, \quad D_{i n t}^{E D A}=\left(\frac{n t}{4 c_{2}}\right)^{2} .
$$


The optimal demand and profits read:

$$
q_{\text {int }}^{E D A}=\frac{n^{2} t}{8 c_{2}}, \quad T_{i n t}^{E D A}=\frac{n^{2} t^{2}}{16 c_{2}} .
$$

The condition on the total demand $q_{1}+q_{2} \leq n$, taking into account $q_{\text {int }}^{E D A}$ establishes $n t-4 c_{2} \leq 0$. This last condition can be rewritten as: $t \leq 4 c_{2} / n$.

\section{B.3. Boundary equilibrium $(D=0)$ : EOA equilibrium}

It can be easily proved that $E O A$ equilibrium is unfeasible.

Replacing $O=0$ in (B1) and (B3), and solving this system of two equations, one has two possible solutions. The first solution establishes:

$$
p_{\text {int }}^{E=A}=\frac{t(\delta-\theta)}{\delta+\theta}, \quad O_{i n t}^{E D A}=\left(\frac{n t \theta(\delta-\theta)}{4 c_{1}(\delta+\theta)}\right), \quad D_{\text {int }}^{E D A}=0 .
$$

A positive price imposes $\delta-\theta>0$.

The demand reads:

$$
q=-\frac{1}{2} n(\delta-\theta) \sqrt{O}
$$

Therefore, a positive price implies a negative demand, and hence, this first option is unfeasible.

The second possibility with $D=0$ is $O=0$, and in this case, both the demand and the optimal profits are zero. 